\title{
Smart growth comparison in two specific cities
}

\author{
Huanjing Lao \\ North China Electric Power University(Baoding), Baoding 071000, China \\ 547458477@qq.com
}

Keywords: Principal Component Analysis(PCA),smart growth,Grey Prediction

\begin{abstract}
In these years, some of the cities' continued urban sprawl and the loss of farmland which is surrounding urban centers causes their development out of balance. It does great harm to a country as well as people's happiness. Smart growth is a theory which comprehensively gives the solution to this problem. So we build a contribution evaluation model for the first class indicators and ranking their potentials in each city and then analyze result . Finally, We use analogy simulation to get the data we need in 2050.To begin with, we try to select another two cities that have similar geographical position with Chishui and Heshan but develop faster than them. Meanwhile, they meet the requirement of the same station of development when their populations are approached with the current populations of Chishui and Heshan. Thus, the predicted data can be replaced approximately with new cities' data collected in the year when their population approached to $150 \%$ of the current populations of Chishui and Heshan. In this way,our optimized model works out the predicted success of smart growths in 2050.Finally, Chishui scores 2.6341 and Heshan scores 3.5267. Comparing the result with what we forecast before, we can confidently say that our plans support this level of growth in population.
\end{abstract}

\section{Introduction}

\subsection{Backgrounds}

In order to achieve sustainable and stable development planning objectives in the long term, we should establish a reasonable model to evaluate the urban development plan and then give our advisable measures. Considering demographics, growth needs, and geographical conditions of a city as well as other important factors, we will proceed as follows:

- Base on the metric models to rank the individual initiatives as the most potential to the least potential, then compare the differences.

- Find the point of a 50 percent increase in population compared to the current ones of Chishui and Heshan and the time of these two points are ahead of 2016.

\section{Model}

\subsection{Optimized Metric Model-OMM}

\subsubsection{Construction of OMM}

By analyzing the data of two cites based on the principal component analysis we get the extends of each city's smart growth. Whereas some flaws obviously exist. We have just analyzed the degree of correlation of all factors but neglected how they harmoniously develop. For example, we can't greatly develop a city's economy because of his backward economy but overlook his environment and other aspects So what we obtained based on principal component analysis only is imperfect.

So our evaluation model needs optimizing. Firstly, we give the definition- coordinated development coefficient to guide the strategy of our plans. Then we'd further discuss the relationship of these four factors including population, economy, environment and society. Finally, a new metrical model to evaluate the smart growth of a city will be given.

In the same way, we use PCA to calculate the comprehensive scores of each first level indicator and provide no more tautology about theory and process here. Following the steps above, we can get the expression: 


$$
H=\sum_{i=1}^{r} \mu_{i} f_{i}
$$

in which $H$ denotes the comprehensive scores. Thus, the scores of population, economy, environment and society can be worked out.

(1). Elimination of negative numbers and zeros.

Due to the exists of negative number scores, our next step of calculating coordinated development coefficient will be difficult. In order to avoid this situation, we firstly need to do linear scaling transformation to pretreat the data, which accompanies the appearance of number-zero. Then using the ideal of efficacy coefficient to do a further transformation and the formula is as follow:

$$
H_{i j}=\frac{g r_{i j}-\min \left\{g r_{j}\right\}}{\max \left(g r_{j}\right)-\min \left\{g r_{j}\right\}} \times(1-n)+n \quad(1 \leq j \leq m)
$$

In which $H_{i j}$ denotes the $\boldsymbol{i}$-th indicator's score in $\boldsymbol{j}$ city. $\boldsymbol{m}$ stands for the number of the first level indicators.

(2). comprehensive development level of a city

Based on the analysis above, the formula of a city's comprehensive development level can be summed up as:

$H(i, j, s, t)=\kappa_{1} H_{i}+\kappa_{2} H_{j}+\kappa_{3} H_{s}+\kappa_{4} H_{t}$

$H(i, j, s, t)$ stands for the score of this city's comprehensive development level which consists of population level, economical level, environmental level and social level. $\kappa_{1} \cdots \kappa_{4}$ denotes every factors' weight in this evaluation system.

(3). Calculating the coordination degree

We are ready to design the coordination degree formula by Benefit theory and Equilibrium theory. The goal of Benefit theory is to get largest efficiency with his influential factors' synchronous development. And Equilibrium theory focuses on the balance among each factors. In other words, you can not get benefit maximization

with the sacrifice of some relatively less important factors.

Basing on all of above, we can design another formula:

$\psi(i, j)=\frac{H_{i} H_{j} H_{s} H_{t}}{\left(H_{i}+H_{j}+H_{s}+H_{t}\right)^{2}}$

$\psi(i, j)$ represents the first level indicators' development.

Using average efficiency benefit index to replace comprehensive benefit index and standardize $\psi$ ( express the coordination degree):

$$
\psi(i, j)=\left\{\frac{H_{i} H_{j} H_{s} H_{t}}{\left(\frac{\left.H_{i}+H_{j}+H_{s}+H_{t}\right)^{4}}{4}\right.}\right\}^{K}
$$

In which $K$ denotes coordination coefficient and $K \geq 2$

Therefore, our final goal- coordination coefficient development formula is as follow:

$\operatorname{Dev}=\sqrt{\psi H(i, j, s, t)}$

In which $H(i, j, s, t)$ stands for the scores of a city's comprehensive smart growth. 
Table 1 Divisions and evaluation standard of $\psi$ Maladjustment interval

\begin{tabular}{|c|c|c|c|c|c|c|}
\hline \multirow{2}{*}{\multicolumn{4}{|c|}{$\psi \quad$ evaluation }} & \multirow{2}{*}{\multicolumn{2}{|c|}{$\psi$}} & \\
\hline & & & & & & evaluation \\
\hline \multicolumn{2}{|c|}{$0-0.09$} & \multicolumn{2}{|l|}{ Extreme imbalance } & \multicolumn{2}{|c|}{$\begin{array}{l}0.50-0.5 \\
9\end{array}$} & Reluctantly coordinated \\
\hline \multicolumn{2}{|c|}{$\begin{array}{c}0.10-0.1 \\
9\end{array}$} & \multicolumn{2}{|l|}{ Serious imbalance } & \multicolumn{2}{|c|}{$\begin{array}{l}0.60-0.6 \\
9\end{array}$} & Primary coordination \\
\hline \multicolumn{2}{|c|}{$\begin{array}{l}0.20-0.2 \\
9\end{array}$} & \multicolumn{2}{|l|}{ Moderate imbalance } & \multicolumn{2}{|c|}{$\begin{array}{l}0.70-0.7 \\
9\end{array}$} & Intermediate coordination \\
\hline \multicolumn{2}{|c|}{$\begin{array}{c}0.30-0.3 \\
9\end{array}$} & \multicolumn{2}{|l|}{ Mild imbalance } & \multicolumn{2}{|c|}{$\begin{array}{c}0.80-0.8 \\
9\end{array}$} & Good coordination \\
\hline \multicolumn{2}{|c|}{$\begin{array}{l}0.40-0.4 \\
9\end{array}$} & \multicolumn{2}{|c|}{ On the verge of imbalance } & \multicolumn{2}{|c|}{$\begin{array}{c}0.90-1.0 \\
0\end{array}$} & Great coordination \\
\hline \multicolumn{7}{|c|}{ Table 2 Divisions and evaluation standard of $\mathrm{Dev}$} \\
\hline \multicolumn{3}{|c|}{ Acceptable interval } & \multicolumn{4}{|c|}{ Unacceptable interval } \\
\hline & \multirow{2}{*}{\multicolumn{2}{|c|}{$\begin{array}{l}\text { evaluatıon } \\
\text { Extreme imbalance recession }\end{array}$}} & \multicolumn{2}{|c|}{ Dev } & \multicolumn{2}{|r|}{ evaluation } \\
\hline & & & 0.50 & & \multicolumn{2}{|l|}{ Relu } \\
\hline & \multicolumn{2}{|r|}{$\begin{array}{l}\text { Serious imbalance } \\
\text { recession }\end{array}$} & \multicolumn{2}{|c|}{$\begin{array}{c}0.60-0.6 \\
9\end{array}$} & & mary coordination development \\
\hline & \multicolumn{2}{|c|}{$\begin{array}{l}\text { Moderate imbalance } \\
\text { recession }\end{array}$} & \multicolumn{2}{|c|}{$\begin{array}{l}0.70-0.7 \\
9\end{array}$} & \multicolumn{2}{|c|}{ Intermediate coordination development } \\
\hline & \multicolumn{2}{|r|}{$\begin{array}{l}\text { Mild imbalance } \\
\text { recession }\end{array}$} & \multicolumn{2}{|c|}{$\begin{array}{l}0.80-0.8 \\
9\end{array}$} & \multicolumn{2}{|r|}{ Good coordination development } \\
\hline & \multicolumn{2}{|c|}{$\begin{array}{l}\text { On the verge of imbalance } \\
\text { recession }\end{array}$} & \multicolumn{2}{|c|}{$\begin{array}{c}0.90-1.0 \\
0\end{array}$} & & $\begin{array}{l}\text { Great coordination } \\
\text { development }\end{array}$ \\
\hline
\end{tabular}

\subsubsection{Improved Results and Analysis}

Being improved, our result has a great change accompanying with the optimization of the basic evaluation metric model. Two cities' coordinated development coefficient is:

$$
\begin{aligned}
& \psi_{\text {Heshan }}=2.1412 \\
& \psi_{\text {Chishui }}=0.6895
\end{aligned}
$$

Compared with Chishui, Heshan is seems more developed. In order to make our results more intuitive, we have made a radar chart of population, economy, environment and society. Therefore, the real development will be displayed directly.

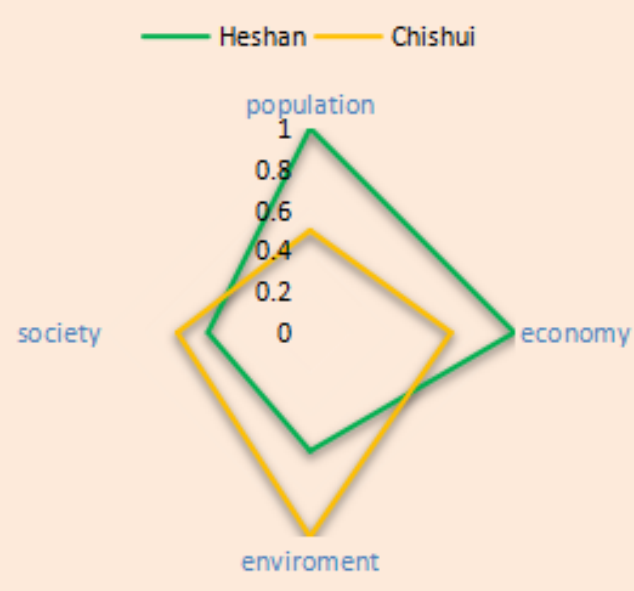

Heshan is ahead of Chishui in the economy and population although. But in terms of environment and society, Chishui's comprehensive environmental score is still higher than Heshan.

Then the new result is respectively:

$$
\begin{aligned}
& \text { Znew }_{\text {Heshan }}=1.3253 \\
& \text { Znew }_{\text {Chishui }}=0.7516
\end{aligned}
$$


Chishui's success score has increased, while Heshan has declined. This result is more reasonable than the former. After all, because of Chishui's historical conditions, its tourism industry is potential. Thus the development between these two cities can't exist much difference. The amendment of the model result in the decline of Heshan's score. That's to say, some hidden defects and risks which can't be ignored are reflected.

\section{Analysis}

Reasons for the changes of Chishui

Population: Due to the development of tourism and tertiary industry as well as the improvement of people's awareness of health and leisure, the number of people moving in and settling begins to grow,leading to the fast decline of environment.

Enviroment: It tends to be steady at the beginning. Based on the expansion of the city and the development of tourism, environmental conditions will experience a dramatic decline without interference and strict control. When people's wealth accumulation reaches to a certain level, people will focus on the environment governance and then environmental conditions begin to gradually take on a new look.

Society:With the improvement of people's living standard and the development of transportation, Engel's coefficient starts to decrease, and people's consumption consciousness starts to increase. According to statistics, when the average wage reaches a certain number, this performance will become much more obvious.

Economy: growing faster while environment starts to deteriorate.

$\checkmark$ change reasons of Heshan

Population: For it is originally saturated and subjected to restrictions on the size of the city, the population grows slowly at the beginning. And the improvement of environment accelerates the growth.

Enviroment: In order to attract investors and talents from outside, Heshan must response to national call and carry out ongoing clean engineering to get faster development.

Economy and Society: With the breakthrough of environment, people' life and working environment have been greatly improved, so does the improvement of enthusiasm. Because of the excellent geographical position, the tertiary industry develops with a rapid rate which accounts for the increase number of settled enterprises and acceleration of increased per capita GDP. Society has the same situation.

We use two cities' data in 2016 as the initial data, and then combine with the intervention trends of population, economy, society and environment to give the smart growth rate of each city.

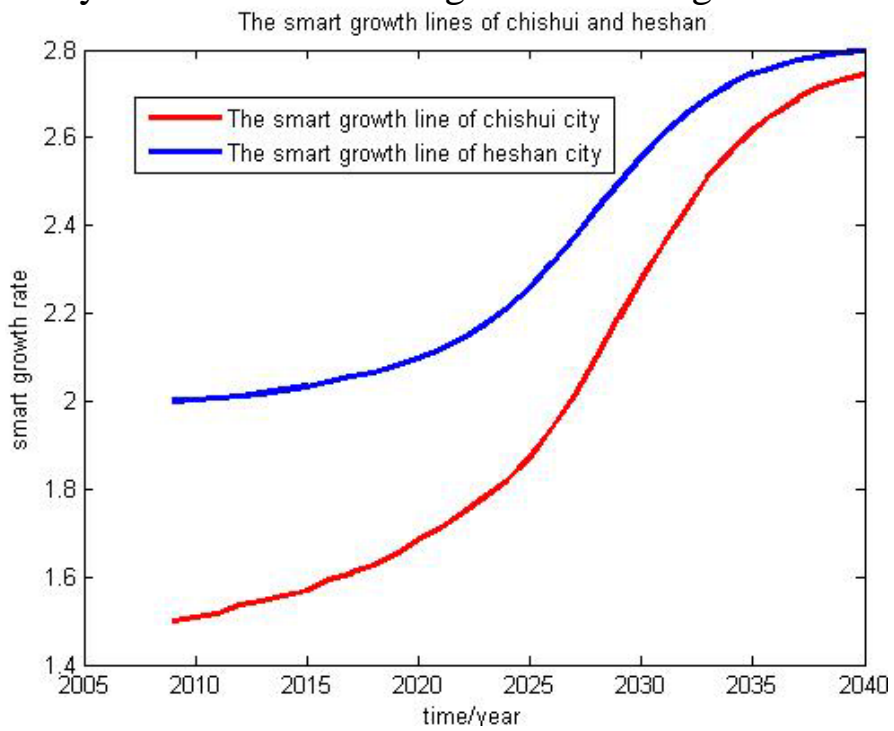

We will implement our plan from 2016. From the figure above, we can find that in first several years, the smart growth rate of the two cities are relatively slow. Once crossing the bottleneck, the 
rapid qualitative leap will appear. Restricted by coordinated development, each city will become stable ultimately. The most gratifying thing is that when Chishui's potential is developed, its success of smart growth is basically the same as Heshan's.

\section{Future Work}

\begin{tabular}{c|cccc}
\hline type & $\begin{array}{c}\text { Contribution in } \\
\text { Chishui City }\end{array}$ & Ranking & $\begin{array}{c}\text { Contribution in } \\
\text { Heshan City }\end{array}$ & Ranking \\
\hline Population & 0.0546 & 3 & 0.0476 & 4 \\
Economy & 1.0468 & 1 & 0.1112 & 3 \\
Environment & 0.0216 & 4 & 0.5248 & 1 \\
Society & 0.2521 & 2 & 0.275 & 2 \\
\hline
\end{tabular}

\subsection{Rank Potential Initiatives}

Because assessing and ranking the first level indicators -population, environment, society and economy are under different urban smart growth, we can't measure them separately by scores or weights, but do further discussion and refinement on the original basis. Refer to the relevant literature, we define the contribution as follows:

$$
\begin{aligned}
& \chi=r w * \zeta \\
& r w_{i}=\frac{S_{i}}{\sum_{j=1}^{4} S_{j}} * C^{i} \\
& C^{i}=\frac{2-S_{i}}{s_{i}}
\end{aligned}
$$

In which $r w_{i}$ denotes the ith improved weigh and $C^{i}$ denotes the ith Coordinate correction coefficient.

We have already calculated the variable's value in our papers above. So we will give the ranking of each city's indicators.

From the ranking we get above, it is obviously to see that the contribution of each factor to the city is different. Also, the same factor performs different in two cities. In Chishui City, economic indicators contributes the most, which indicates that Chishui needs to develop economy most to increase its smart growth rate. In Heshan city, the most important contribution indicator is environment because Heshan's unhealthy economic development has led to the deterioration of the environment.Thus environmental factors have the greatest impact on the smart growth.

\subsection{Our way to Support Population Growth \\ Our new idea about prediction}

Once a city develops in the case of 50\% rate of population growth, how will all indicators change in the end? This is a difficult problem to estimate. Because different cities have different trends, the development trend basing on itself and the outside world's influence in all aspects. In this issue, we need to regard population as the main factors. So we will not simply do assumption which ignores the impact of other factors. Therefore, we give the following ideas:

Re-select the two cities which meet:

the current development is better than the Chishui City and Heshan City

- their geographical location is close to Chishui City and Heshan city

- When the populations of these two cities were close to Chishui and Heshan, their development was similar to Chishui and Heshan respectively.

- Find the point of a 50 percent increase in population compared to the current ones of Chishui and Heshan and the time of these two points are ahead of 2016.

Therefore, we collect the data of the new selected cities respectively in the certain different years to forecast the result by our optimized model the same as before. In this way, each city's predicted success of smart growth can be given.

Finally, Chishui scores 2.6341 and Heshan scores 3.5267. Comparing the result with what we forecast before, we can confidently say that our plans support this level of growth in population. 


\section{References}

[1]. wikipedia,Retrieved from https://en.wikipedia.org/wiki/Smart_growth

[2]. Linan Luo1,Lifu Xie 2-.Analysis of climatic resources of Ecotourism in Chishui city.Journal Of Guizhou Meteorology.2010;34(01):0030-03.

[3]. FeiZheng,Zhuying Zhang.Research on the Coordinate Development Models of the Learning City Large-scale Systems.Value Engineering.2016;06:0245-03.

[4]. Peng Du1, Bing Xia2,Lei Yang3.Study on the Valuation Index System of National Central City Intelligent Development.Science \& Technology Progress and Policy.2016;30(06):0108-05.

[5]. Peiji Shi,Yinfeng Yang,Yanfang Wu. Evaluation Model of Urban Sustainable Development Coordination Based on Compound System.Statics and Decision Making.2010;14:0036-03 